\author{
Víctor FERNÁNDEZ SALINAS \\ Departamento de Geografía Humana, Universidad de Sevilla
}

\title{
El reconocimiento patrimonial de los cementerios en las grandes ciudades andaluzas
}

\section{RESUMEN}

Los cementerios son uno de los recursos patrimoniales más complejos $\mathrm{y}$, a la vez, desconocidos. Durante los últimos decenios se ha avanzado en el reconocimiento de estos lugares hasta convertirlos en recursos turístico-culturales de primer orden. Los cementerios de las grandes ciudades andaluzas ofrecen un buen ejemplo de estos argumentos, aunque la situación varía considerablemente de unas ciudades a otras. Con este trabajo se propone una primera selección interrelacionada de los principales valores asignados a estos lugares: los relacionados con los registros lapidarios; los histórico-artísticos y literarios; los ligados a la memoria histórica; y los ritual-simbólicos y legendarios.

\section{RÉSUMÉ}

Le reconnaissance patrimonial des cimetières à les grandes villes andalouses.- Les cimetières sont une des ressources patrimoniales plus complexes et, en même temps, inconnues. Durant les dernières décennies, il y a eu des progrès dans la reconnaissance de ces sites jusqúà devenir une ressource touristique-culturelle de premier ordre. Les cimetières des villes andalouses offrent un bon exemple de ces arguments, bien que la situation varie considérablement entre elles. Ce travail propose une première sélection des principales valeurs attribuées à ces endroits: celles qui sont liées aux pierres tombales; les historique-ar-

\section{INTRODUCCIÓN}

$A^{\prime}$ pesar de que el reconocimiento patrimonial a los cementerios ha aumentado notablemente durante los últimos decenios hasta el punto de convertirse, incluso, en importantes reclamos turísticos, la cultura española ha tardado en incorporar este recurso patrimonial y, a la hora de hacerlo, ha primado el valor de su materialidad artística antes que sus componentes inmateriales. Sin tistiques et littéraires; la memoria histórica; et les rituel-symboliques et légendaires.

\section{Abstract}

Heritage recognition on cemeteries in the great Andalusian cities. Cemeteries are one of the most complex heritage resources and, at the same time, unknown. During the last decades there has been progress in the recognition of these sites till become fundamental tourist and cultural resources. Cemeteries of the Andalusian cities offer good examples of these arguments, although the situation varies considerably from cities to others. This work proposes a first selection of the main values assigned to these places: those related to lapidary records; those historic-artistic and literary ones; those linked to the memoria histórica; and the ritual-symbolic and legendary ones.

\section{Palabras clave/Mots clé/Keywords}

Andalucía, cementerios, patrimonio cultural, proceso de patrimonialiación, memoria histórica.

L'Andalousie, cimetières, patrimoine culturel, procès de patrimonialiación, memoria histórica.

Andalucia, cemeteries, cultural heritage, process of patrimonialiación, memoria histórica.

embargo, durante los últimos años la situación está cambiando y Andalucía no es una excepción a la tendencia general. Los cementerios de sus ciudades más pobladas ofrecen un interesante elenco de datos e informaciones que permiten conocer el grado de aprecio patrimonial a este tipo de bienes culturales. Por ello se ha optado por los municipios que superan los cien mil habitantes: las capitales provinciales más Algeciras, Dos Hermanas, Jerez de la Frontera y Marbella. En ellos, se conside- 
ran aquellos cementerios que responden a los principios de salubridad e higiene creados desde principios del siglo XIX y que nacen con una vocación de estabilidad para sustituir los numerosos cementerios provisionales construidos con motivos de las numerosas epidemias de aquel siglo.

Entre las motivaciones que justifican la prelación que se otorga a estos cementerios pueden citarse las siguientes:

a) Son cementerios que han asumido valores, bien asignados por las instituciones (académicas, legales, patrimoniales, etc.), bien por la base social, que han sometido su consideración y percepción a importantes cambios a través del tiempo. Su lectura patrimonial es, en consecuencia, compleja y necesaria.

b) Las dinámicas urbanas de las ciudades más pobladas han establecido lógicas espaciales complejas y variadas respecto a sus cementerios, ya que estos han sido objeto de cambios objetivocuantitativos (ampliaciones, desplazamientos, etc.), y cualitativos-perceptivos (apropiaciones simbólicas, nuevos significados, etc.) con mayor frecuencia e incidencia que en las ciudades medias y pequeñas. Por ello sus camposantos engloban, aunque no agotan, las principales características patrimoniales de los cementerios andaluces.

c) En estos camposantos se ha asentado con contundencia la huella de la burguesía andaluza, que, si bien de carácter distinto y no comparable numéricamente a la de otras regiones españolas, también impuso en los cementerios su impronta de exhibición pública. La segregación social y diferenciación formal tienen también su trasunto en el cementerio y estos aspectos son menos destacables en las localidades medias y pequeñas.

d) Los hechos históricos que poseen proyección en los cementerios son más complejos y potentes en las grandes ciudades, tanto en lo que respecta al número de personajes que poseen reconocimiento institucional o popular, como en lo que atañe a la huella de sucesos acaecidos en la población a la que pertenecen.

En razón de lo anterior, el trabajo que se presenta persigue los siguientes objetivos:

- Reflexionar sobre los significados patrimoniales de los cementerios.
- Analizar el proceso de patrimonialización de los cementerios andaluces e identificar el estadio en que se encuentran los que son objeto de este trabajo. A estos efectos, se diferenciará entre los que están en fase incipiente; los que han alcanzado un reconocimiento patrimonial maduro; y los que están en fase regresiva.

- Incorporar los testimonios de la memoria histórica en los discursos patrimoniales sobre los cementerios andaluces.

- Recoger percepciones patrimoniales de distinta clase y consideración sobre estos cementerios.

A efectos de este artículo, se tienen en cuenta los cementerios que continúan en activo y aquellos que, ya sin uso, aún poseen vestigios significativos. Es importante señalar que cada cementerio es entendido como una unidad espacial continua que forma una pieza claramente identificada en el entramado urbano, aunque pueda ser diferenciado internamente y con accesos distintos entre cementerio católico, de otras creencias religiosas y civil.

Entre los camposantos no incluidos se encuentra el cementerio mancomunado de la Bahía de Cádiz, en donde desde 1992 se inhuman los fallecidos en la capital provincial, por ubicarse en Chiclana de la Frontera y responder a una escala supramunicipal. También se han despreciado algunos cementerios que pertenecen a localidades menores de los términos municipales de las ciudades seleccionadas (San Antonio de Churriana [Málaga], San Pedro de Alcántara [Marbella] o Santa Cruz [Córdoba]). Al contrario, sí se incluye un cementerio que en su día perteneció a una entidad aislada, pero que en la actualidad está plenamente insertado en el tejido urbano de Málaga: el de San Juan en El Palo.

Las fuentes bibliográficas utilizadas y citadas se aportan al final del artículo. Se ha trabajado con varios expedientes de declaración de bien de interés cultural y con otros documentos afines a partir de la página web de la Consejería de Cultura de la Junta de Andalucía. Respecto al Atlas del patrimonio inmaterial de Andalucía, se ha utilizado la página web del Instituto Andaluz del Patrimonio Histórico. Se ha realizado un seguimiento de las principales hemerotecas digitales locales; se han consultado varias páginas relacionadas con la utilización de los cementerios como lugares de ajusticiamiento y enterramiento durante la guerra civil y posguerra, especialmente la de la Asociación para la Recuperación de la Memoria Histórica, y se ha realizado un trabajo de campo de recogida de datos, textos e imágenes. 


\section{LOS CEMENTERIOS COMO RECURSO PATRIMONIAL}

\section{Aspectos Generales}

En la vida cotidiana, el cementerio se ha consolidado como el lugar de la conmemoración familiar a las personas allí enterradas, especialmente en determinadas fechas. Desde el punto de vista íntimo y subjetivo, el sentimiento de nostalgia y dolor ante la pérdida de personas allegadas es bastante homogéneo y cercano entre culturas, por mucho que se puedan establecer diferencias entre los ritos que unas y otras desarrollen. En cambio, desde la perspectiva de su proyección pública y ritual, las diferencias son mucho más notables.

Existen tres dimensiones básicas del proceso de patrimonialización de los cementerios: el reconocimiento artístico, el histórico y el ritual-simbólico. El proceso suele iniciarse con la valoración de la dimensión artística que poseen mausoleos, esculturas y jardines de corte neoclásico y ecléctico construidos en los cementerios europeos y otras zonas del planeta durante el siglo XIX. Aquella patrimonialización primó lo excepcional o curioso frente a valores de representatividad o cotidianeidad. Desde finales de aquel siglo se consolida la valoración de los cementerios como repositorios históricos de la localidad a la que pertenecen. En ellos se puede encontrar, junto a inhumaciones de personas sin trascendencia histórica, las de individuos que destacaron por algún hecho y que merecieron un reconocimiento público y las de individuos no destacados o incluso anónimos pero que responden a una agrupación determinada (comunidades religiosas o de otro tipo que reciban sepultura colectiva) o a un evento histórico (muertos en frente de batalla, fusilados por determinadas revueltas o revoluciones, etc.). Pero este carácter de mediador histórico también suscita discusión dado que se trata a menudo de hechos y sucesos no sólo con significados cambiantes con el tiempo (Tarrés y Moreras, 2012), sino que no son compartidos siempre por todos los grupos sociales de la localidad a la que sirven. La percepción sobre los cementerios es pues cambiante y depende de múltiples, complejas y, a veces, curiosas vicisitudes ${ }^{1}$.

El fallecimiento del cantante y compositor Jim Morrison a los 27 años en París en 1971 y su inhumación en el cementerio de Père Lachaise ha transformado en buena parte la percepción de este cementerio, de tal forma que el tratamiento y número de visitas a la tumba de este artista ha terminado empequeñeciendo a personajes tan ilustres como Oscar Wilde, Apollinaire, Modigliani, Miguel Ángel Asturias o María Callas, entre otros muchos.
Desde el punto de vista de los valores ritual-simbólicos, la lectura de los cementerios es aún más compleja. En este sentido resulta de interés la mirada antropológica, más centrada en los valores inmateriales, que ha aportado conocimiento, tanto en lo que respecta a los ritos que se suceden durante determinadas fechas como a la asignación de valores a estos lugares (Candáu, 2002; Lacarrieu, s. f., en línea). En este sentido es destacable la aparición de asociaciones de amigos de cementerios en muchos países (Argentina, Estados Unidos, Reino Unido, etc.). Pero, a menudo, la incorporación de elementos patrimoniales relacionados con la muerte y hechos históricos luctuosos ha dado lugar a expresiones como las de bienes «disonantes» (Tunbridge y Ashworth, 1996), «indeseables» (Prats, 2005) o incluso «hirientes» (Uzzell y Ballantyne, 1998).

En los últimos años, estas tres dimensiones se interrelacionan en la determinación del valor patrimonial de los cementerios, sobre todo cuando adquieren el carácter de recurso turístico cultural, lo que obliga a proyectos de gestión compleja (Matero y Peters, 2003; Ragon, 1983). Además, y aunque se trate de un proceso muy reciente, comienzan a aparecer organizaciones y redes de escala internacional para el reconocimiento de las necrópolis. Así, se constituye en 2000 la Red Iberoamericana de Valoración y Gestión de Cementerios Patrimoniales y, como resultado de sus encuentros, en el de 2005 se elabora la Carta internacional de Morelia relativa a cementerios patrimoniales y arte funerario. En el contexto europeo, en 2001, surge la Asociación Europea de Cementerios Singulares (ASCE). Como resultado de sus trabajos, el Consejo de Europa incluyó entre sus itinerarios culturales la Ruta Cultural Europea de Cementerios, en la que se integran 67 necrópolis de 54 ciudades en veinte países europeos. No obstante, el hecho de que no exista ningún cementerio como tal en la Lista del Patrimonio Mundial de la Unesco, compuesta por 1.031 bienes, evidencia la inmadurez del reconocimiento patrimonial internacional hacia estos espacios.

\section{Algunas apreciaciones Sobre el CONTEXto español}

En España, existe un buen número de monografías sobre cementerios con aproximación patrimonial o con importante información para su lectura cultural, pero aquellas que presentan una vocación supralocal son escasas (Calatrava, 1991; González Díaz, 1970; Quirós Linares, 1991; Santonja, 1998-1999) y en pocas ocasiones producto de encuentros científicos en los que se debatan 
sus valores. El primero que se celebró con cierta relevancia fue el organizado por la Junta de Andalucía en 1991 (Primer Encuentro Internacional sobre los Cementerios Contemporáneos, Consejería de Presidencia, 1993).

El desconocimiento, la precariedad o inexistencia de inventarios y los registros parciales o desacertados, unidos a una cierta desidia de los ayuntamientos, de quienes suele depender la gestión de los cementerios, han provocado la pérdida de muchos de sus valores y una sustitución sin criterio de elementos (especialmente de espacios abiertos con inhumaciones y su colmatación con bloques de nichos) que han provocado en muchos casos su perdida de carácter y su banalización. También podría apuntarse la escasa consideración urbanística de los cementerios como bienes culturales, lo que habitualmente los relega a contextos inapropiados y, cuando terminan insertados en un ámbito colmatado, son expulsados a lugares alejados de los centros urbanos, lo que suele conllevar la pérdida de buena parte de sus valores.

No obstante, hay signos de cambio en la apreciación de los cementerios españoles más allá de las publicaciones científicas y expedientes de protección. No se trata sólo de que hayan aparecido también aquí algunas asociaciones de amigos de los cementerios (Alicante, Orense, Vitoria, Málaga, entre otras), sino que existen iniciativas nuevas, como la de la revista Adiós Cultural (cuyo proyecto editorial publica la Guía cultural y turística de cementerios españoles), que ya ha realizado dos concursos anuales sobre los mejores cementerios del país y que, en la edición de 2015, recoge, además del Premio al Mejor Cementerio en su Conjunto, otros a la Mejor Escultura, Mejor Historia Documentada y Mejor Iniciativa Medioambiental (este último con reglas específicas). Los premios se otorgan por un jurado que tiene en cuenta una votación popular, que ya supera los 10.500 participantes. En algunos lugares (Luarca [Asturias], Comillas [Cantabria], etc.), sus camposantos se están activando como recursos turísticos de primer orden; en otros (entre los que destaca el de Torrero, en Zaragoza) se convierten en escenarios de una interesante oferta cultural. En Finisterre se le ofreció el proyecto de nuevo cementerio a un relevante arquitecto español de renombre internacional, César Portela, y aunque pese a su vocación de integración paisajística y reconocimientos internacionales (finalista en los premios Philippe Rotthieer en 2002 y Mies van der Rohe en 2003), el camposanto continúa vacío, es un buen signo de que las percepciones sobre los cementerios en España son hoy muy distintas a las de hace pocos decenios.

\section{ASPECTOS GENERALES SOBRE LOS CEMENTERIOS DE LAS GRANDES CIUDADES ANDALUZAS: TIEMPOS Y ESPACIOS}

Lo que diferencia a los cementerios andaluces de otros españoles es, en el orden físico, un acercamiento a las prácticas arquitectónicas tradicionales locales, especialmente en el uso de materiales. También existe una lógica relación entre las especies vegetales ornamentales y las variadas características climatológicas andaluzas, que aconsejan y hacen más frecuentes unas especies que otras. En el orden inmaterial, la relación con la muerte posee también algunas características propias (Muñoz Gil, 1990; Rodríguez Becerra, 1997), que, aunque no son objeto de este trabajo, serán retomadas parcialmente más adelante en tanto que explican el proceso de patrimonialización de los cementerios considerados.

Desde el punto de vista de los tiempos y espacios de los camposantos analizados, se puede hablar de cuatro generaciones:

\section{LA PRIMERA GENERACIÓN DE CEMENTERIOS CONTEMPORÁNEOS: PRIMERA MITAD DEL SIGLO XIX}

Con los cementerios construidos en este periodo (Cuadro I) culminan los intentos, muchas veces infructuosos o parciales, de las disposiciones sobre enterramientos que venían produciéndose desde el siglo anterior. A este labor ayudaron poderosamente las epidemias (fiebre amarilla en 1800, cólera en 1833-1834, etc.). Éstas habían estado presentes en muchas ocasiones a lo largo de la historia, pero el arraigo de las ideas higienistas, el mayor tamaño de las poblaciones y las disposiciones legales y normativas acabaron por asentar las necrópolis extramuros. Se trata de cementerios que, o bien han desaparecido, o se conservan sin uso, o fueron profundamente replanteados desde mediados del siglo XIX (como el de Las Barreras de Granada, ampliado y convertido en el de San José). Algunos se conservan, al menos en alguna de sus trazas, por su relevancia histórica (San Rafael de Málaga) o artística (San Eufrasio de Jaén), o se han convertido casi en museos al aire libre (Cementerio Inglés de Málaga). Sin embargo, el de San José de Cádiz está siendo desmantelado y abocado a su desaparición en pocos años. En la mayor parte de los casos, y aunque la ubicación inicial fuese el extrarradio, estos cementerios poseen en la actualidad una ubicación intraurbana, salvo en el caso de Granada, que se sitúa en el borde de la ciudad (Fig. 1). 
CUADRO I. Los cementerios de las grandes ciudades andaluzas: generación, origen, uso y ubicación actuales

\begin{tabular}{|c|c|c|c|c|c|}
\hline Ciudad & Cementerio & Generación & Origen & Uso actual & Localización actual \\
\hline Granada & C. de las Barreras-San José & $1^{\text {a }}$ Generación & 1805 & En uso & Borde urbano \\
\hline Almería & Cementerio de Belén & & 1810 & \multicolumn{2}{|c|}{ Desaparecido } \\
\hline Málaga & San Miguel & & 1810 & Sin uso desde 1987 & Intraurbana \\
\hline Córdoba & Nuestra Señora de la Salud & & 1811 & En uso & Intraurbana \\
\hline Cádiz & San José & & 1815 & Sin uso desde 1992 & Intraurbana \\
\hline Sevilla & San Sebastián & & 1819 & \multicolumn{2}{|c|}{ Desaparecido } \\
\hline Huelva & Cabezo de San Pedro o Viejo & & 1823 & \multicolumn{2}{|c|}{ Desaparecido } \\
\hline Jaén & San Eufrasio o del Calvario & & 1829 & Sin uso desde 2003 & Borde urbano \\
\hline Málaga & Cementerio Inglés & & 1830 & En uso & Intraurbana \\
\hline Sevilla & San José o de Triana & & 1833 & \multicolumn{2}{|c|}{ Desaparecido } \\
\hline Jerez de la Frontera & Santo Domingo & & 1834 & \multicolumn{2}{|c|}{ Desaparecido } \\
\hline Cádiz & Cementerio de los Ingleses & & 1842 & \multicolumn{2}{|c|}{ Desaparecido } \\
\hline Algeciras & Cementerio Antiguo o Viejo & 2. ${ }^{\mathrm{a}}$ Generación & 1849 & En uso & Intraurbana \\
\hline \multirow[t]{2}{*}{ Sevilla } & San Fernando & & 1852 & En uso & Intraurbana \\
\hline & San Jorge o de los Ingleses & & 1855 & Sin uso desde fin $\mathrm{xx}$ & Intraurbana \\
\hline Huelva & San Sebastián & & 1858 & \multicolumn{2}{|c|}{ Desaparecido } \\
\hline Málaga & San Juan (El Palo) & & 1865 & En uso & Intraurbana \\
\hline Almería & San José & & 1866 & En uso & Intraurbana \\
\hline Málaga & San Rafael & & 1867 & Sin uso desde 1987 & Intraurbana \\
\hline Dos Hermanas & San Sebastián & & 1875 & \multicolumn{2}{|c|}{ Desaparecido } \\
\hline Marbella & San Bernabé & & 1885 & En uso & Intraurbana \\
\hline Dos Herm. & San Pedro & 3. ${ }^{\text {a }}$ Generación & 1909 & En uso & Borde urbano \\
\hline Huelva & Nuestra Señora de la Soledad & & 1928 & En uso & Borde urbano \\
\hline Jerez de la Frontera & Nuestra Señora de la Merced & & 1943 & En uso & Borde urbano \\
\hline Jaén & San Fernando o Cementerio Nuevo & & 1972 & En uso & Borde urbano \\
\hline Málaga & Parque Cementerio de Málaga & 4. ${ }^{\text {a }}$ Generación & 1987 & En uso & Periurbana \\
\hline Córdoba & Nuestra Señora de Fuensanta & & 1988 & En uso & Periurbana \\
\hline Marbella & Virgen del Carmen & & 1989 & En uso & Periurbana \\
\hline Cádiz & C. Mancom. Bahía de Cádiz & & 1992 & En uso (Chiclana) & Metropolitana \\
\hline Algeciras & Parque Jardín Cementerio & & 2001 & En uso & Periurbano \\
\hline
\end{tabular}

Fuente: Consejería de Cultura (en línea, a), Quirós Linares (1991), Rodríguez Barberán y Ramos Guerra (1993). Elaboración propia.

\section{LA SEGUNDA GENERACIÓN DE CEMENTERIOS: SEGUNDA MITAD DEL SIGLO XIX}

Desde mediados del siglo XIX, no sólo son necesarias ampliaciones, sino que a menudo son necesarios nuevos emplazamientos (San Fernando de Sevilla [Fig. 2] o San José de Almería) por la inadecuación o centralidad que habían adquirido algunos de los construidos durante los primeros decenios del siglo. Esto motiva la desapari- ción de algunos (San Sebastián en Dos Hermanas, San Sebastián en Huelva, etc.). También se realizan incorporaciones, más orgánicas que planificadas, de espacios para cementerios civiles o de otras confesiones religiosas (aunque ya existían precedentes como el Cementerio Inglés de Málaga [1830] y el de los Ingleses de Cádiz [1842]); con lo que la estructura y realidad morfológica de las necrópolis se hacen más complejas y compartimentadas. Esto es especialmente significativos en los ce- 


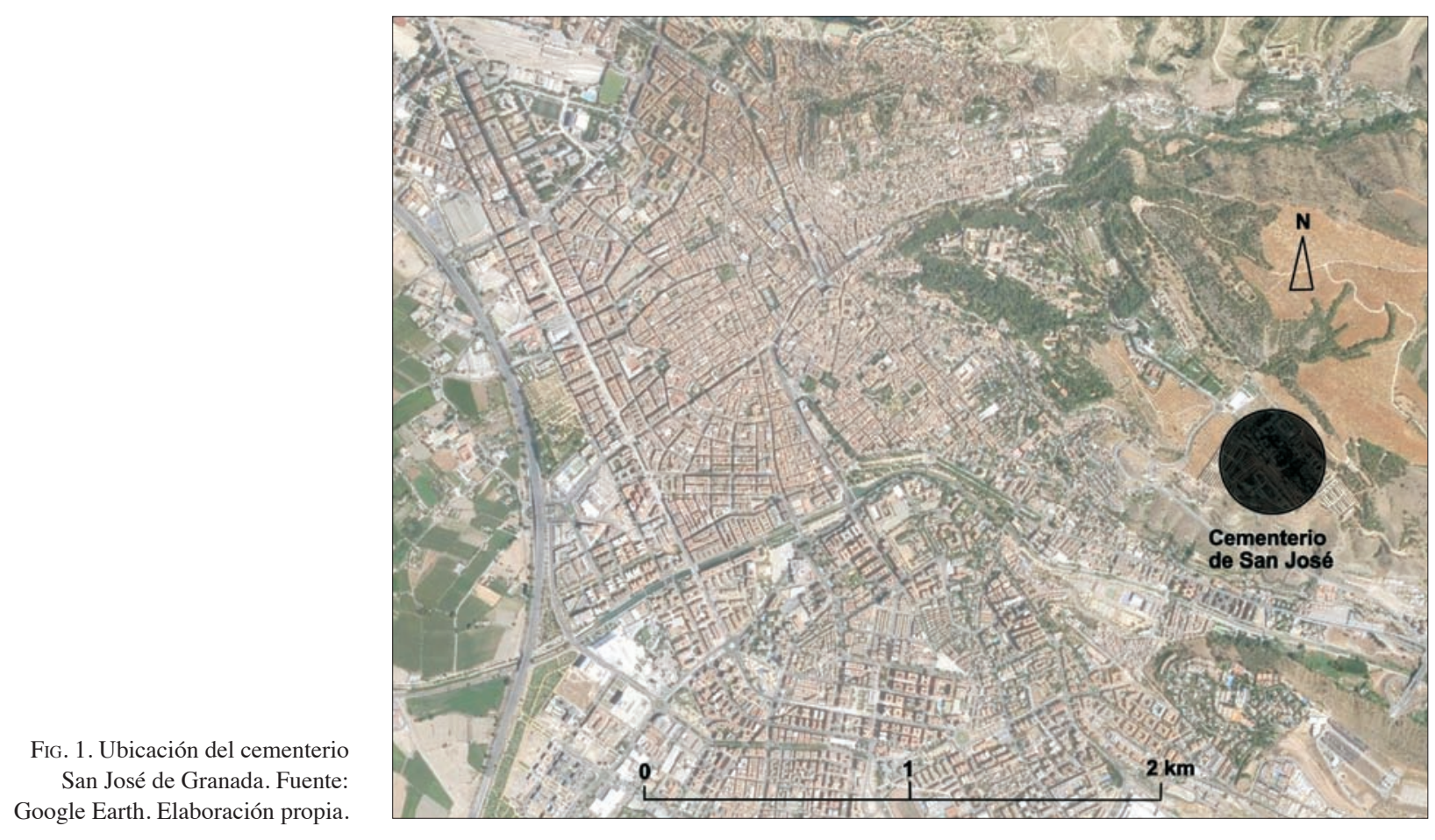

menterios civiles (Jiménez Lozano, 2008), no entendidos en su época como un derecho regulado para los no católicos, sino para quienes, como herejes contemporáneos, elegían o eran condenados al no futuro. El concordato de 1851 señala expresamente que no pueden inhumarse en los cementerios católicos los apóstatas, excomulgados, suicidas, duelistas, restos incinerados y pecadores públicos (Nistal, 1996); ello aboca a que se cree la ley de 1855, que permite la construcción de cementerios civiles. Esto da pie a que en Andalucía éstos aparezcan paulatinamente junto a los principales camposantos o en otros emplazamientos. En la actualidad, todos los que se conservan poseen una situación intraurbana.

\section{TERCERA GENERACiÓN DE CEMENTERIOS:}

DESDE LOS INICIOS HASTA LOS AÑOS SETENTA DEL SIGLO XX

La tercera generación de cementerios también sustituye emplazamientos anteriores; sin embargo, no es tan numerosa, con lo que puede afirmarse que el sistema de cementerios de las ciudades analizadas se crea en su mayor parte en el siglo XIX. Los camposantos de tercera generación incorporan un planteamiento más urbanístico, si bien en las distintas claves del decenio en el que fueron construidos. Se trata pues de instalaciones que, de ser la ciudad apartada y a menudo negada, pasan a formar parte del compendio de equipamientos que debe reunir, con criterios técnico-higiénicos de ubicación y gestión, cualquier población. Todos los creados durante este período se encuentran en activo y poseen una localización de borde urbano (Nuestra Señora de la Merced de Jerez [Fig. 3], San Pedro de Dos Hermanas, Nuestra Señora de la Soledad de Huelva, etc.).

\section{Cuarta generación de cementerios: DESDE LOS AÑOS OCHENTA DEL SIGLO XX}

Se puede hablar, finalmente, de cementerios andaluces de cuarta generación, aquellos que se crean en los años ochenta y noventa del siglo xx, algunos de ellos llamados «parques cementerio» o denominaciones similares (Algeciras, Córdoba, Málaga y Marbella), lo que viene a indicar un cambio de concepto que los acerca más, al menos en la terminología, a los modelos anglosajones. Sin embargo, pese a su denominación y una disposición formal más libre y abierta, los contenedores de cadáveres o cenizas siguen siendo, salvo excepciones, la línea de bloques de nichos consolidada durante el siglo xx. Estas necrópolis son equipamientos que han asumido los planeamientos urbanísticos de lo que en su momento 


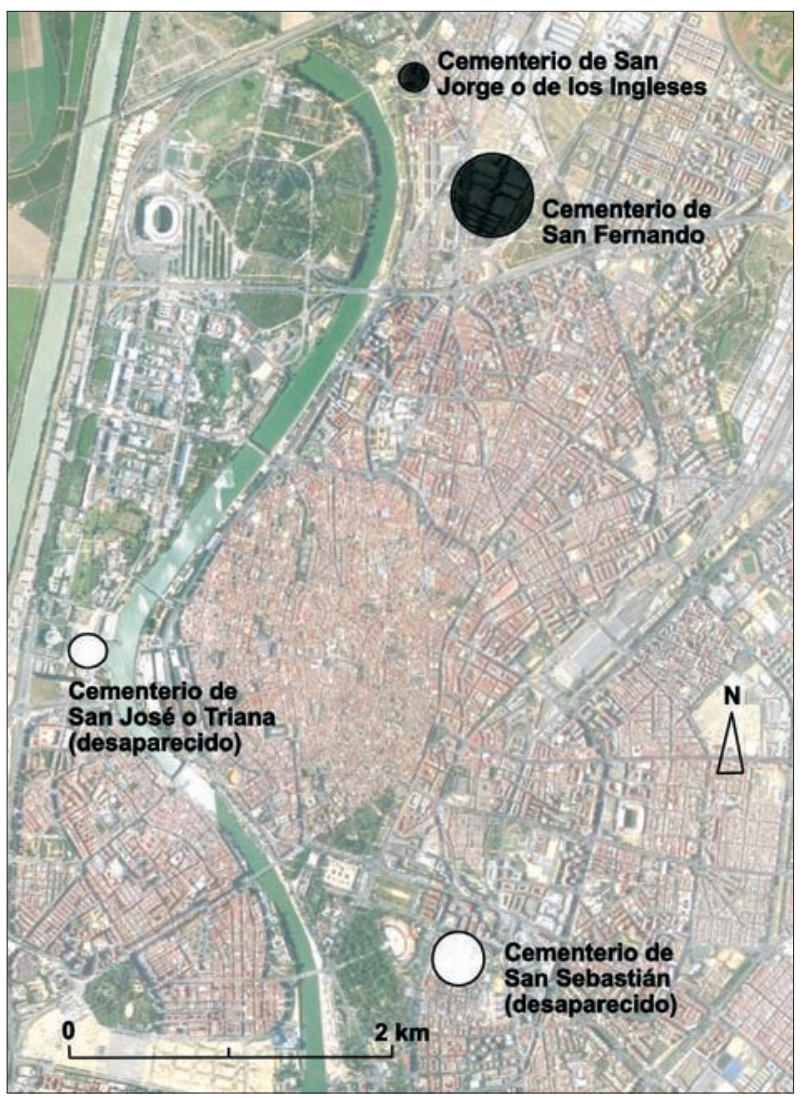

FIG. 2. Ubicación de los cementerios de Sevilla. Fuente: Google Earth. Elaboración propia.

ya era la tercera oleada de planes generales en las ciudades españolas; pero, a diferencia de las sustituciones anteriores, casi todas, salvo en los casos de San Miguel y San Rafael de Málaga, conviven con las construidas en el siglo XIX. Además, en el de San Miguel el columbario permanece activo. Otro aspecto de interés es que han perdido (Parque Jardín Cementerio de Algeciras), o semi esconden, su adscripción al catolicismo en su denominación, como es el caso del Parque Cementerio de Málaga, ligado a san Gabriel, pero al que no se nombra en la presentación de su página web. En cuanto a su ubicación, los nuevos cementerios tienen una localización periurbana y, en el caso del Parque Cementerio de Málaga, la distancia al centro supera los ocho kilómetros ${ }^{2}$ (Fig. 4).

\footnotetext{
${ }^{2}$ El Cementerio Mancomunado de la Bahía de Cádiz, a más de veinte kilómetros de la capital, no incluido en este trabajo, podría considerarse también en esta cuarta generación o, incluso, que abre una quinta en la que los cementerios se conciben y mancomunan en las áreas metropolitanas o espacios intensamente urbanizados.
}

\section{LOS VALORES PATRIMONIALES DE LOS CEMENTERIOS ANDALUCES}

La asignación de valores patrimoniales a los cementerios andaluces se expresa en un complejo y multidireccional sistema de apreciaciones. Éstas se pueden sintetizar en los siguientes:

- valores asociados a registros lapidarios familiares y de reconocimiento a colectivos y personajes destacados;

- valores histórico-artísticos y literarios;

- valores ligados a la memoria histórica;

- valores ritual-simbólicos y legendarios.

Esta diferenciación es, antes que nada, de carácter operativo, puesto que lo más frecuente es que estos valores se entremezclen y que su evolución genere interrelaciones diferentes a través de los años. Respecto a cada uno de ellos, interesan, a efectos de este artículo, tanto su proceso de patrimonialización como la inclusión de algunas percepciones y valoraciones representativas.

\section{Valores asociados a REgistros lapidarios FAMILIARES Y DE RECONOCIMIENTO A COLECTIVOS Y PERSONAJES DESTACADOS}

\section{A) El proceso de patrimonialización}

La memoria lapidaria expresa o bien palabras que se atribuyen al difunto, o bien sentencias que le dedican su familia, amigos, admiradores o instituciones. Se trata de un proceso semejante al que aparece en otros cementerios del mundo y no se puede considerar que cada mensaje constituya un elemento patrimonial en sí mismo; el reconocimiento proviene de la consideración global de todos ellos. Aunque existen lugares comunes y fórmulas de expresión repetitivas en los epitafios, también abundan los textos reflexionados y que sintetizan en una o pocas frases el sentimiento de conexión entre fallecido y allegados.

Respecto al homenaje colectivo a personajes destacados en lápidas u otro tipo de registros, se identifica sobre todo con próceres (políticos, literatos, benefactores, etc.) y otros personajes famosos. Su huella gana presencia y significado desde mediados del XIx. Panteones y esculturas de toreros (como los de Lagartijo o Manolete [Fig. 5] en el cementerio de Nuestra Señora de la Salud de Córdoba, o los de Joselito el Gallo o Juan Belmonte 
FIg. 3. Ubicación de los cementerios de Jerez de la Frontera. Fuente: Google Earth. Elaboración propia.

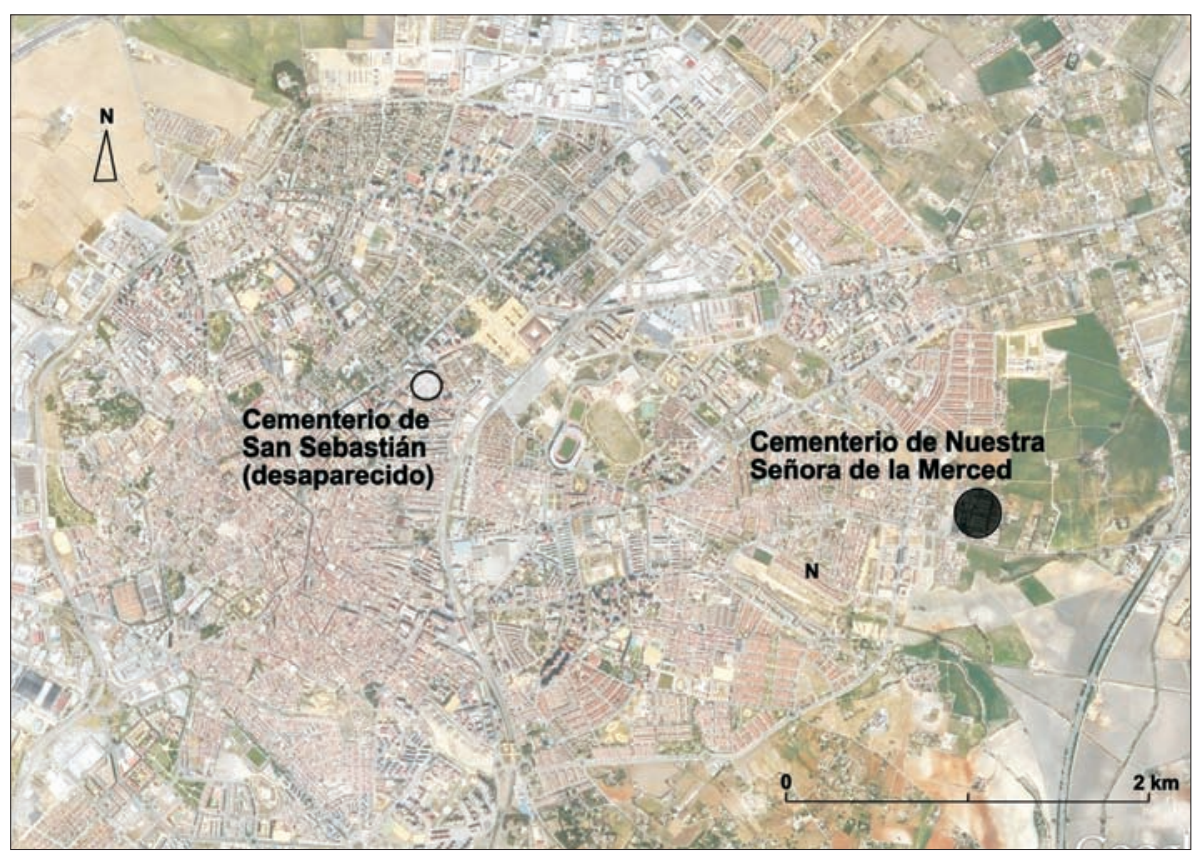

en el de San Fernando de Sevilla) o de artistas flamencos (Lola Flores en el cementerio de San Fernando de Sevilla [Fig. 6] o Paco de Lucía en el Cementerio Viejo de Algeciras) hacen patente esta práctica en la que se combinan, a menudo, reconocimientos tanto populares como institucionales.

Por otro lado, los enterramientos colectivos debidos a hechos luctuosos o a acontecimientos históricos (fallecidos en las guerras de África o del «bando nacional» de la guerra civil [Fig. 7], etc.) tienen también homenaje destacado en los cementerios de las grandes ciudades andaluzas (cruces de los Caídos en Algeciras, Almería o Granada, panteones de Falange en Cádiz, etc.).

\section{B) Percepciones: transcripciones lapidarias ${ }^{3}$}

a) Sentencias atribuidas al difunto

Si me buscáis, buscadme en vuestros corazones, si me encontráis sigo vivo en vosotros.

(Cementerio de San José de Granada)

Nos dijeron que no éramos de aquí, que éramos viajeros, gente de paso, huéspedes de la tierra, camino de las nubes.

(Cementerio de San José de Granada)
Un hombre sin Dios es como un perro sin amo. (Cementerio de San Fernando de Sevilla)

\section{b) Mensajes familiares}

Here lies a man forever kind, of gentle, loving, noble mind. Through our tears we all can see how God can live in you and me [«Aquí yace un hombre siempre amable, de mente gentil, afectiva y noble. A través de nuestras lágrimas todos podemos ver cómo Dios puede vivir en ti y en mí»].

(Cementerio Inglés de Málaga)

Me diste tu amor y tu vida. Llenaste mi corazón y me lo dejas vacío, lo diste todo por todos. La vida ya sin ti no tiene sentido. Tu esposo. (Cementerio de San José de Granada)

Yayo: Has sido un padre ejemplar, día a día lo demostraste, me lo diste todo sin pedir nada a cambio [...]. Yayo, has sido el mejor abuelo del mundo, nos diste a mi hermana y a mí todo el amor del mundo. [...] ¡Cuánto te quiero, Yayito!

(Cementerio de San Fernando de Sevilla)

c) Recuerdos a personajes destacados y a colectivos

Insigne precursor de la corriente Occidentalizante. Ilustre investigador de la Cultura Ibérica. Apasionado amante de la Historia de España. D. Luis Soto-Aranaz Jiménez [...]. Honremos al árbol cuya sombra nos protege.

(Cementerio de San José de Granada)

Aquí yacen sesenta y un soldados muertos en esta ciudad de las heridas que recibieron en África, peleando como buenos por la

\footnotetext{
${ }^{3}$ Todos los textos han sido recogidos in situ.
} 


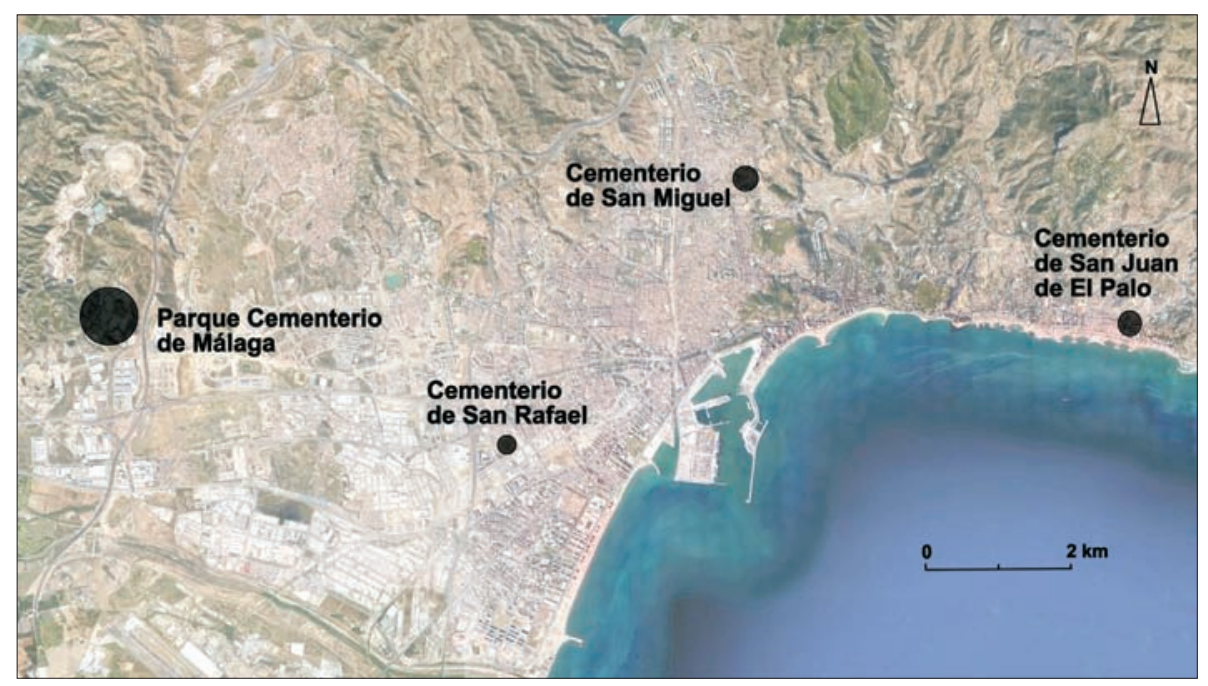

FIG. 4. Ubicación de los cementerios de Málaga. Fuente: Google Earth. Elaboración propia. honra de su patria en guerra contra los moros. Para conservar a las generaciones venideras el glorioso recuerdo de su heroico valor, Sevilla erigió este sepulcro. Año de 1861.

(Cementerio de San Fernando de Sevilla)

El Parque de Artillería de Sevilla dedica este recuerdo como prueba de la memoria de sus obreros muertos en el cumplimiento del deber a consecuencia de la explosión que tuvo lugar el día 28 de abril de 1937 en el pabellón del Aceite de la Exposición IberoAmericana habilitado por necesidades de la guerra redentora en taller de artificios.

(Cementerio de San Fernando de Sevilla)

\section{VALORES HISTÓRICO-ARTÍSTICOS Y LITERARIOS}

\section{A) El proceso de patrimonialización}

a) Los valores histórico-artísticos

El interés patrimonial institucional en Andalucía hacia los cementerios da un paso importante en 1986, cuando se lleva a cabo una serie de trabajos auspiciados por la Junta de Andalucía para dar a conocer sus valores artístico-arquitectónicos (Fig. 8), escultóricos (Fig. 9) y botánicos. Se trataba de llamar la atención ante el proceso, que continúa activo, de las renovaciones sin criterio, especialmente con la generalización del sistema de nichos a costa de las inhumaciones. El trabajo generó como principal producto un preinventario de diseños espaciales y arquitectónicos de calidad. Así, en 1993, vio la luz la publicación Cementerios de Andalucía. Arquitectura y urbanismo (Rodríguez Barberán y Ramos Guerra, 1993) publicada por la misma Junta de Anda- lucía. En esta obra se destacan y analizan los aspectos generales y comunes a todos los cementerios (cerca, portada y acceso, dependencia, organización y distribución interior, jardinería y sistema de sepulturas), además de realizar una reflexión general sobre las necrópolis y su relación con la ciudad a la que pertenecen. La obra se completa con la presentación de 28 cementerios singulares o representativos. De ellos, sólo cuatro pertenecen a las ciudades objeto de este trabajo: San José de Almería, San José de Cádiz; Cementerio Inglés de Málaga y San Fernando de Sevilla.

Sin embargo, la protección legal a los cementerios, basada fundamentalmente en su carácter histórico-artístico, es mucho más reciente, ya que la mayor parte de las declaraciones no alcanza los diez años. Se han inscrito ocho en el Catálogo General del Patrimonio Histórico Andaluz (Cuadro II). De los cuatro cementerios andaluces con la consideración de bien de interés cultural, sólo uno se ubica en las grandes ciudades: el Cementerio Inglés de Málaga (Fig. 10), declarado en 2012.

La inclusión de algunos camposantos en la antedicha Asociación Europea de Cementerios Singulares, ASCE (Nuestra Señora de la Salud de Córdoba, San José de Granada y Cementerio Inglés de Málaga) dio pie a que éstos formasen parte desde 2010 de uno de los también citados itinerarios culturales del Consejo de Europa, la Ruta de los Cementerios Europeos. Sin embargo, la activación de las necrópolis de las grandes ciudades andaluzas dista mucho de ser un recurso cultural para ser compartido entre propios y visitantes. Los que poseen una proyección más alta son los de San José de Granada y, con diferencia, el Cementerio Inglés de Málaga. Respecto al de San 


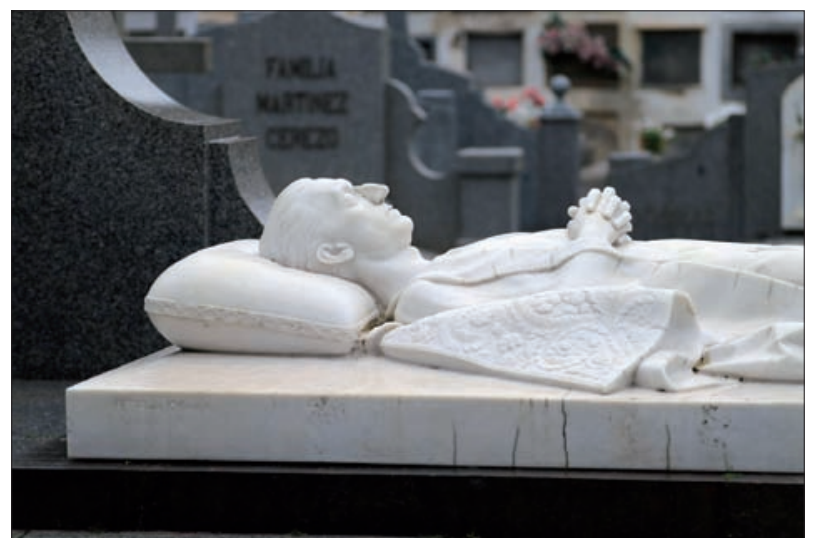

FIg. 5. Tumba de Manolete, de Amadeo Ruiz Olmos, en el cementerio de Nuestra Señora de la Salud de Córdoba. Fotografía del autor.

José, el Ayuntamiento está haciendo una apuesta importante por incorporarlo a sus recursos culturales y turísticos (Fig. 11) y posee también una notable visibilidad en las fuentes electrónicas. Del segundo puede encontrarse una nutrida información en bibliografía especializada, en las descripciones de viajeros y, en general, en internet sobre sus valores y sobre cómo y cuándo visitarlo. Los cementerios de Nuestra Señora de la Salud de Córdoba, San Miguel de Málaga y San Fernando de Sevilla presentan una proyección media. De ellos es relativamente fácil obtener información y recursos para sus visitantes, pero aún son marginales en la oferta patrimonial de sus correspondientes ciudades. También hay algunos camposantos con proyección y visibilidad menores: reciente en el Cementerio Viejo de Algeciras y algo más asentada en los de Nuestra Señora de la Soledad de Huelva y San Rafael de Córdoba. No exento de valores ni de cierta visibilidad (aunque casi siempre haciendo notar su estado ruinoso) está el cementerio de San Eufrasio de Jaén. En el resto de las necrópolis la valoración como recurso turístico-cultural es irrelevante y los cementerios de San José de Cádiz o de San Jorge o de los Ingleses en Sevilla son objeto de destrucción y olvido.

\section{b) Los valores literarios}

Desborda absolutamente el objeto de este artículo revisar en profundidad la presencia de los cementerios en la literatura andaluza contemporánea. Baste señalar algunas ideas fuerza. Desde el siglo XIX, los conceptos de cementerio y ciudad se confunden en las figuras literarias:

Más ha de quinientos años, en una torcida calle, que, de Sevilla en el centro, da paso a otras principales; cerca de la medianoche,

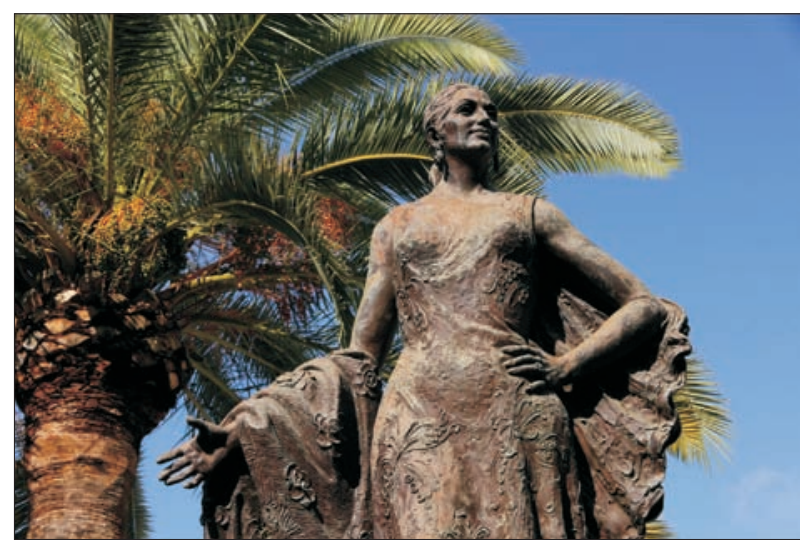

FIG. 6. Tumba de la cantante y bailaora Lola Flores en el cementerio de San Fernando de Sevilla. Fotografía del autor.

cuando la ciudad más grande es de un grande cementerio en silencio y paz imagen. (Ángel Saavedra, Duque de Rivas: «Una Antigualla de Sevilla. Romance I», Romances históricos, 1841)

Los cementerios encuentran también lugar en discursos costumbristas:

Quiéreme parecer, Juan, que tienes la manga más ancha que la puerta del cementerio, por donde caben todos los que van y sobra sitio para los que vienen. (Luis Coloma: Caín, 1873)

En el siglo xx, la abrumadora calidad y cantidad de autores andaluces también toma como protagonista la figura del cementerio como trasunto del estado del alma o de las geografías personales de los autores:

Mira, éste es el patio de San José. Ese rincón umbrío y verde, con la verja caída, es el cementerio de los curas... Este patinillo encalado que se funde, sobre el Poniente, en el sol vibrante de las tres, es el patio de los niños... Anda... El Almirante... Doña Benita... La zanja de los pobres, Platero... (Juan Ramón Jiménez: «El Cementerio Viejo», Platero y yo, 1914)

Estas constantes están muy presentes en la generación del 27, destacando sobre todo la figura de Luis Cernuda, uno de los autores que más utilizó la necrópolis como argumento poético («Elegía anticipada», «Cementerio en la ciudad», «Las ruinas», etc.). Esta relación continúa en autores más recientes, como Antonio Gala, cuya obra teatral Los verdes campos del Edén se desarrolla precisamente en un camposanto y que, en su artículo «Cementerio», señala:

Lo he dicho y lo repito: me gustan los cementerios. De una ciudad, antes que nada, visito los mercados y los cementerios. Son su haz y su envés: cómo viven sus vivos, cómo viven sus muertos. 


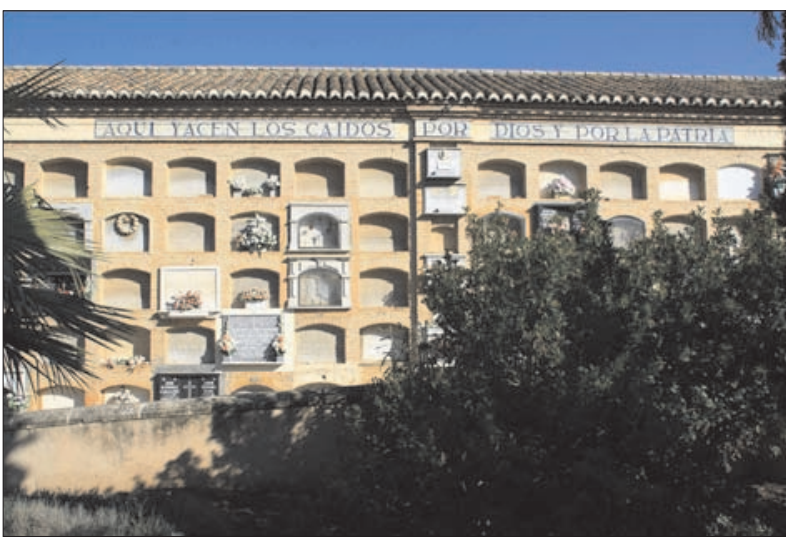

Fig. 7. Pabellón dedicado originalmente a los «Caídos por Dios y por la Patria» en el cementerio de San José de Granada. Fotografía del autor.

(Antonio Gala, citado por E. Girón Irueste y A. Arenas Gómez, 2003, p. 366)

Pero, a pesar de esta mirada reiterada de la literatura andaluza a la necrópolis, no son abundantes las referencias a lugares concretos. En otras palabras, en Andalucía se ha patrimonializado más la idea inmaterial del cementerio que los cementerios propiamente dichos y claramente identificados. En la obra literaria, las necrópolis de las grandes ciudades andaluzas suelen aparecer como lugares secundarios, no muy citados y más importantes en su significado que en su significante. Se trata, pues, de una patrimonialización parcial.

\section{B) Percepciones y valoraciones}

a) De la visión histórica-artística

Tiene el microclima de las leyendas brumosas, como un cuento de Poe que arenga al descubrimiento. El desconocido Cementerio Inglés [adosado al de Nuestra Señora de la Soledad de Huelva] enfila su resurrección. Un reducto desconocido de la ciudad de Huelva, abandonado durante décadas, donde descansan algunos de los británicos que explotaron las minas y trajeron a España el fútbol y el golf. [...] La implicación del Ayuntamiento de Huelva se basa en la apreciación de este lugar como parte integrante del patrimonio histórico onubense dentro del denominado «legado británico», que hoy en día se reivindica como parte importante de nuestras señas de identidad y atractivo turístico de la ciudad. (Inma Gallego, 2015)

Notable ejemplo patrimonial [el cementerio de San Eufrasio de Jaén], no sólo por su valor social sino además por el histórico y arquitectónico, conserva en su interior panteones destacados [...]. Al haber sido concebido el cementerio como construcción retirada del casco urbano, se hace necesario crear un polígono aislado del Conjunto Histórico que le conceda protección. (Decreto 272/2011

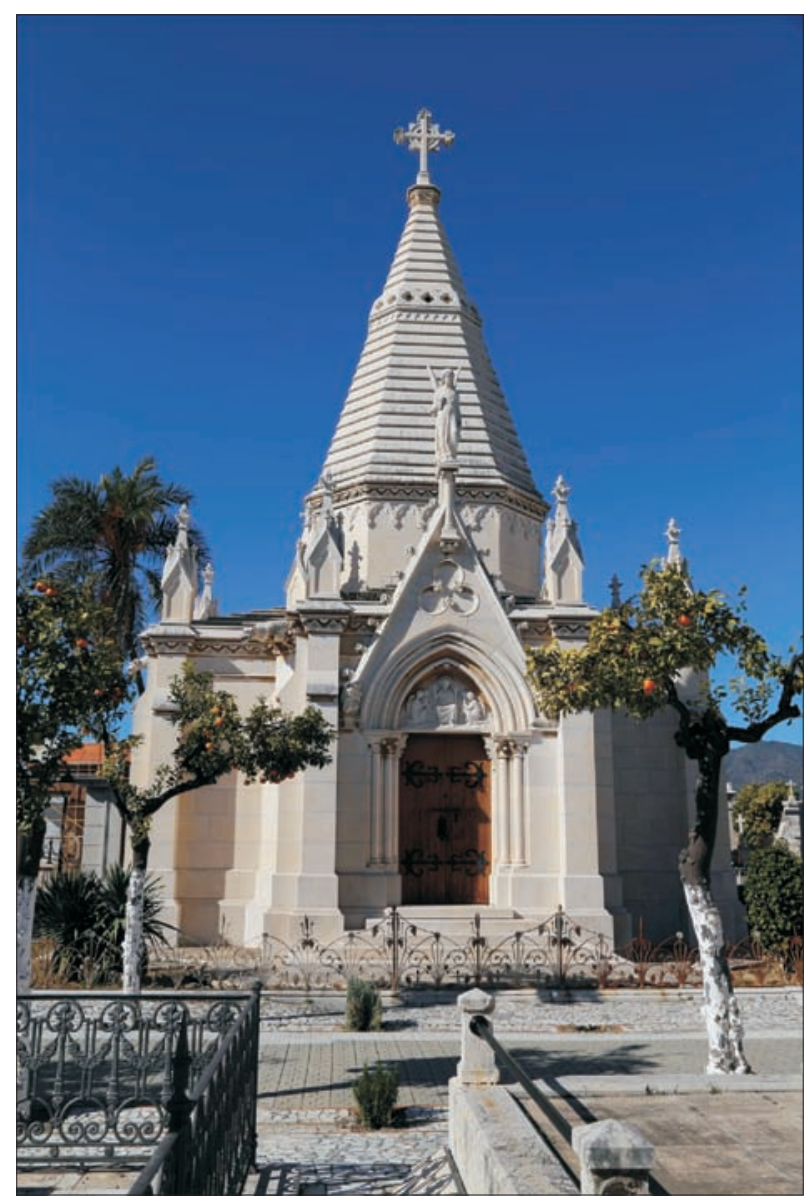

Fig. 8. Panteón de los Larios (1877), obra de Federico Pérez Giménez, en el cementerio de San Miguel de Málaga. Fotografía del autor.

[...] por el que se inscribe en el Catálogo General del Patrimonio Histórico Andaluz la modificación de la delimitación del [...] conjunto histórico, de la ciudad de Jaén)

En el campo artístico, hay que diferenciar entre el recinto y las lápidas, panteones familiares y un monumento colectivo. En el primero predomina la estética neogótica del acceso, frente al gusto neoclásico del frente principal del templo, estética que se trasladó a los enterramientos funerarios, a diferencia del primer recinto donde se localizan unas sencillas pero elocuentes tumbas cubiertas con conchas. (Decreto 524/2012 [...] por el que se inscribe en el Catálogo General del Patrimonio Histórico Andaluz como Bien de Interés Cultural [...] el Cementerio Inglés de Málaga)

\section{b) De la visión literaria}

Entre los que se fueron, por estas avenidas [del cementerio de San Miguel de Málaga] voy más llena que nunca. Roza la primavera mi piel como un anuncio de lo que se avecine. Mármoles y naranjos, el rumor de una abeja y un silencio tan solo comparable al momento en que van a cruzarse dos predestinaciones. Narcisos de- 


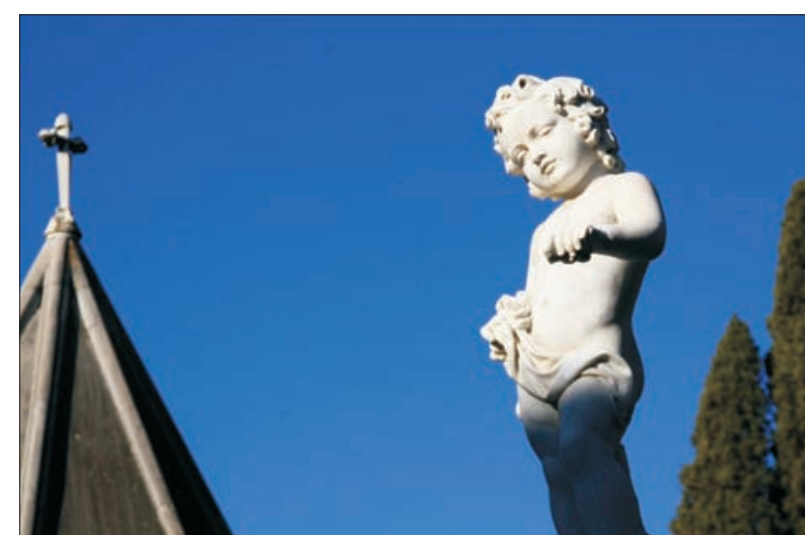

FIG. 9. Escultura en el cementerio de San Fernando de Sevilla Fotografía del autor.

jaré más allá de esta hora y que toquen sus pétalos nombres entrelazados. Fuera de este recinto está el vacío sobre la ciudad anhelante a cuya luz me encuentro con el significado preciso de la vida como un libro que abriese de par en par su verja. (María Victoria Atienza: Entre los que se fueron, 1976)

Mientras esto sucedía, comenzóse a levantar el cementerio [de San Fernando de Sevilla]; la gente huyó de estos contornos, se acabaron las fiestas, los cantares y la música, y se acabó toda la alegría de estos campos, como se había acabado toda la de nuestras almas. (Gustavo Adolfo Bécquer: La venta de los Gatos, 1858-1864)

El cementerio [Inglés de Málaga] desciende, remansado en dolor y recuerdo, y llega casi al mar, rodeado de buganvillas, mimosas y brazos desparramados de araucarias. (Antonio Gala, citado por Ocaña, 2006)

\section{VAlORES LIGADOS A LA MEMORIA HISTÓRICA}

\section{A) El proceso de patrimonialización}

El valor ahora presentado es sin duda histórico, pero de carácter distinto al considerado en el punto anterior. La memoria histórica hace referencia al legado testimonial de un periodo concreto (guerra civil y posguerra) y sucesos (fusilamientos y enterramientos en fosas) que connotan de forma muy diferente a los cementerios. Este valor es el más discutido, entre otras cuestiones porque trata de un proceso histórico aún sin resolver, pese a que hayan pasado más de setenta años de aquellos difíciles sucesos. En el Cuadro III puede apreciarse la entidad de algunas fosas comunes que, por estar ubicadas en ciudades importantes, fueron lugar de fusilamiento, tanto de vecinos como de personas de otras localidades. Particular relevancia poseen los cementerios de Nuestra Señora de

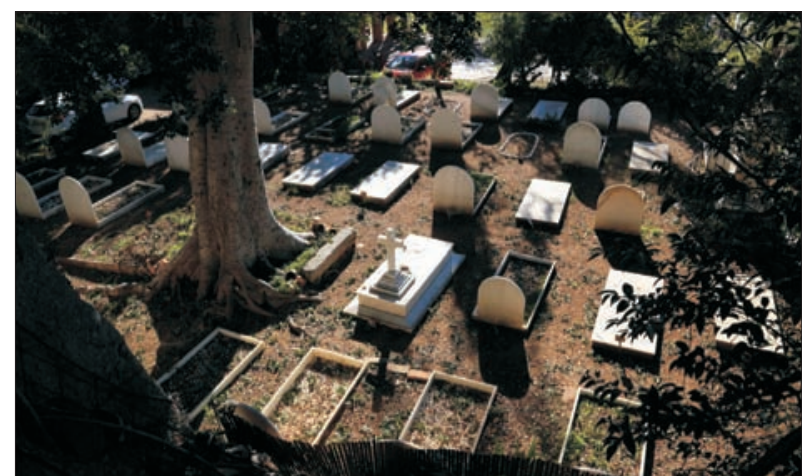

FIG. 10. Cementerio inglés de Málaga. Fotografía del autor.

la Soledad de Huelva, San Rafael de Málaga, San Fernando de Sevilla, San José de Granada y San Pedro de Dos Hermanas; entre los cinco se superan los 18.000 enterramientos en fosas.

El reconocimiento arranca de asociaciones, entre las que destaca la Asociación para la Recuperación de la Memoria Histórica, que, si bien es de carácter nacional, posee un amplia base regional en Andalucía para la investigación, rescate de cadáveres y homenajes. También hay que citar, además de otras de carácter provincial o local, la Asociación Memoria Histórica y Justicia de Andalucía, que mantuvo una importante actividad entre 2003 y 2015, aunque desarrolló mayoritariamente su trabajo en municipios rurales, y la Asociación Pro Derechos Humanos de Andalucía. No son tampoco escasos los programas, proyectos y espacios electrónicos destinados a los mismos objetivos (Todos los nombres, Foro Ciudadano para la Recuperación de la Memoria Histórica, etc.). A menudo, estas asociaciones han conseguido que las instituciones públicas de distintas escalas (municipal, provincial y estatal) asuman sus reivindicaciones. En este sentido, buena parte de los reconocimientos que aparecen en los cementerios (sobre todo columnas, pilares y lápidas) han sido sufragadas, total o parcialmente, por estas instituciones. Además, la Junta promulgó el decreto 264/2011 que crea la figura de lugar de memoria histórica de Andalucía y fosas comunes, que, sin un afán patrimonialista expreso, asume una responsabilidad ética hacia estos valores históricos. Desde 2011 se han declarado cincuenta lugares de memoria histórica de Andalucía y fosas comunes y, entre ellos y relacionados con las necrópolis objeto de este artículo, están los muros de la memoria de los cementerios de Nuestra Señora de la Salud (Fig. 12) y de San Rafael de Córdoba, las tapias del cementerio de San José de Granada y la fosa del cementerio de San Rafael de Málaga. 
CUADRo II. Reconocimiento histórico-artístico de los cementerios de las grandes ciudades andaluzas

\begin{tabular}{|c|c|c|c|c|}
\hline \multirow[b]{2}{*}{ Ciudad } & \multirow[b]{2}{*}{ Cementerio } & \multicolumn{3}{|c|}{ Reconocimiento patrimonial } \\
\hline & & Internacional & Nacional & Autonómico \\
\hline \multirow[t]{2}{*}{ Algeciras } & Cementerio Antiguo o Viejo & - & - & BDPIA \\
\hline & Parque jardín cementerio & - & - & - \\
\hline Almería & San José & - & - & BDPIA \\
\hline Cádiz & San José & - & - & BDPIA \\
\hline \multirow[t]{3}{*}{ Córdoba } & Nuestra Señora de la Salud & ASCE & - & BDPIA \\
\hline & Nuestra Señora de la Fuensanta & - & - & - \\
\hline & San Rafael & - & - & BDPIA \\
\hline Dos Hermanas & San Pedro & - & - & BDPIA \\
\hline Granada & Cementerio de las Barreras-San José & ASCE & - & CGPHA \\
\hline Huelva & Nuestra Señora de la Soledad & - & - & BDPIA \\
\hline \multirow[t]{2}{*}{ Jaén } & San Eufrasio o del Calvario & - & * & BDPIA \\
\hline & San Fernando o Cementerio Nuevo & - & - & BDPIA \\
\hline Jerez de la Frontera & Nuestra Señora de la Merced & - & - & BDPIA \\
\hline \multirow[t]{5}{*}{ Málaga } & San Miguel & - & - & CGPHA \\
\hline & San Juan (El Palo) & - & - & - \\
\hline & Cementerio Inglés & ASCE & BIC & BDPIA \\
\hline & Parque Cementerio de Málaga & - & - & - \\
\hline & San Rafael & - & - & - \\
\hline \multirow[t]{2}{*}{ Marbella } & San Bernabé & - & - & - \\
\hline & Virgen del Carmen & - & - & - \\
\hline \multirow[t]{2}{*}{ Sevilla } & San Fernando & - & - & BDPIA \\
\hline & San Jorge o de los Ingleses & - & - & - \\
\hline \multicolumn{5}{|c|}{ ASCE: Asociación Europea de Cementerios Singulares. } \\
\hline \multicolumn{5}{|c|}{ BDPIA: Base de Datos del Patrimonio Inmueble de Andalucía (Consejería de Cultura). } \\
\hline \multicolumn{5}{|c|}{ CGPHA: Catálogo General del Patrimonio Histórico Andaluz (Consejería de Cultura). } \\
\hline \multicolumn{5}{|c|}{$\begin{array}{l}\text { * La categoría de BIC la tiene el conjunto histórico de Jaén, no el propio cementerio; no obstante, la ampliación de este conjunto histórico en } \\
2011 \text { se hizo, en parte, con el claro objeto de proteger este cementerio (decreto 272/2011). }\end{array}$} \\
\hline
\end{tabular}

Fuente: Asociación Europea de Cementerios Singulares y Consejería de Cultura de la Junta de Andalucía (en línea, $b$ ). Elaboración propia.

\section{B) Percepciones y valoraciones}

Sobre esta primera fosa común, José Sánchez, escribió [...] una Historia de la fosa común de Dos Hermanas, donde describe las características de la fosa, su modo y fechas de funcionamiento y el posible número de víctimas que la ocuparían. Todos estos datos están sacados de conversaciones [...] con los sepultureros de la época que excavaron la fosa y se encargaban de enterrar, con cal y arena, los cadáveres que diariamente llegaban en camiones. [...] La fosa tendría una profundidad media de 3 metros, además, el muro más cercano a la fosa fue derribado para que el camión que llevaba los cadáveres no tuviera más que volcar su macabra carga», Fosa de Dos Hermanas. Sevilla. (Mapa de fosas de las víctimas de la guerra civil y la posguerra en Andalucía, Dirección General de Memoria Histórica de la Junta de Andalucía, en línea)

El viernes pasado día 5 a las 18:30 empezaba el acto formal en que, por sexta vez, se colocaba una «placa» en memoria de las personas fusiladas contra la pared que bordea el cementerio de San José de Granada. En esta ocasión hay motivos para pensar que si la «placa» es arrancada o sufre algún deterioro será consecuencia de acto vandálico de algún o algunos indeseables y no porque el Ayuntamiento, regido por el Partido Popular, al día siguiente ordene a los operarios del cementerio que la arranquen. Es lo que ha hecho en los cinco años anteriores en que la Asociación Granadina para la Recuperación de la Memoria Histórica ha colocado una «placa» 


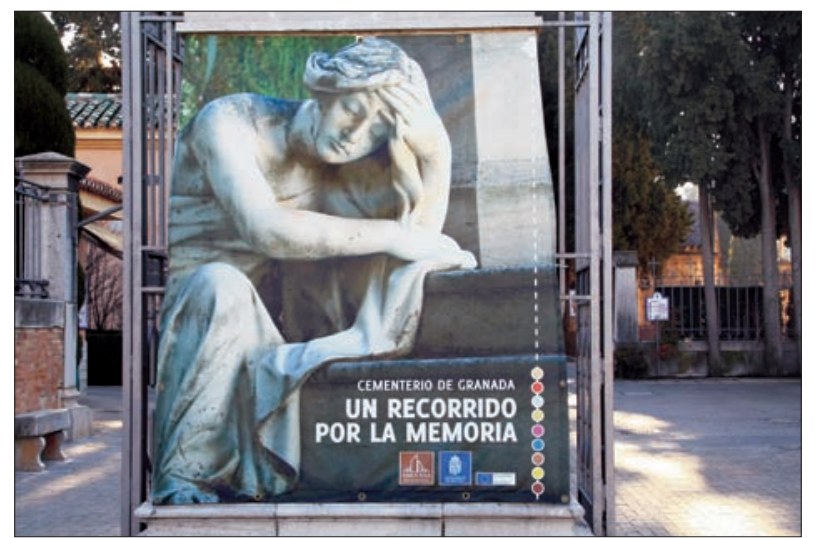

FIG. 11. Cartel publicitario del cementerio de San José de Granada. Fotografía del autor.

en ese lugar para identificarlo y dar constancia de lo allí sucedido. (Jesús Páez: La tapia del cementerio de Granada, 2012)

Las máquinas, mientras tanto, acababan esta semana con los últimos metros de tapia [del cementerio de San Rafael de Málaga] aunque no con toda. Fuentes municipales subrayaron ayer [...] que la portada, con los dos lienzos de muro y la cancela [...], seguirá en pie para respetar el deseo de la Asociación de la Memoria Histórica, aunque no hacía falta, hubiera bastado un mínimo de lógica para concluir que había que respetar la entrada del camposanto, el que llegó a albergar la mayor fosa común de España, que se dice pronto. Ahí está, justo al lado, la pirámide con los restos de 4.500 fusilados por Franco. (Alfonso Vázquez: El retorno al campo del cementerio de San Rafael, 2015)

\section{VALORES RITUAL-SIMBÓLICOS Y LEGENDARIOS}

\section{A) El proceso de patrimonialización}

El cementerio acoge una parte muy sustancial del rito funerario y, además, es el lugar en el que permanece el difunto, por lo que se establece una relación especial entre allegados y lugar de inhumación o depósito, máxime en una sociedad como la andaluza con un concepto conservador de las relaciones familiares. Sin embargo, ya se ha adelantado que, en esta relación, cada familia se vincula con sus difuntos y que no se suelen asignar valores patrimoniales colectivos a los cementerios desde la base popular. Son los estudiosos de la antropología cultural, sobre todo, quienes han forjado una teoría patrimonial basada en los aspectos diferenciales de la cultura andaluza frente a la muerte y el papel que asumen sus necrópolis (Cruz Morales, 1996; Muñoz Gil, 1990). Desde el punto de vista institucional, el afianzamiento del reconocimiento al patrimonio inmaterial durante los últi-

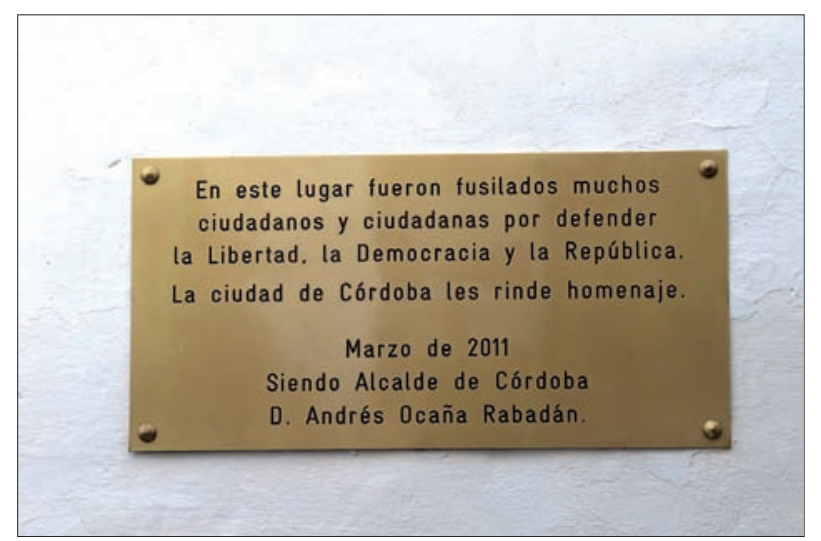

FIG. 12. Muro de la memoria del cementerio de Nuestra Señora de la Salud de Córdoba. Fotografía del autor.

mos decenios está moviendo a la Consejería de Cultura, a través del Instituto Andaluz del Patrimonio Histórico, a la realización, aún inconclusa, del Atlas de patrimonio inmaterial de Andalucía (en línea) que, entre otros aspectos, recoge ritos y expresiones sociales relacionadas con la muerte y los cementerios. Esta información será muy relevante cuando estén disponibles todos sus contenidos, pues en el buscador electrónico actualmente disponible no aparece ninguna entrada «cementerio».

Frente a esta carencia oficial, son abundantes las páginas web en los que se narran sucesos, leyendas y ritos relacionados con los cementerios de las grandes ciudades andaluzas. Además, los ritos anuales, y especialmente en torno a la fecha de Todos los Santos, tienen un amplio eco en los medios de comunicación. El acondicionamiento, limpieza y embellecimiento de lápidas y nichos, obviamente no privativo de Andalucía, moviliza a una buena parte de la sociedad aunque, desde el punto de vista patrimonial, tenga un reconocimiento todavía escaso. Además, en esta línea inmaterial, a veces hay elementos más importantes que las palabras para la proyección de la memoria e identidad del difunto (Fig. 13).

\section{B) Percepciones y valoraciones}

a) Ritual-simbólicas

El último día de octubre más de media Granada sube al cementerio de San José a arreglar las tumbas de sus difuntos. Y todos ellos acaban pasando a presentar sus respetos al Señor del Cementerio. Una escultura de Cristo despojado de sus vestiduras que adorna un panteón familiar privado desde hace más de cien años, que ha acabado generando su propia devoción al tiempo que es testimonio del agradecimiento de los vecinos a un médico local. (José A. Cano, 2013) 
CUADRo III. Cementerios de grandes ciudades andaluzas con valores patrimoniales asignados a partir de la memoria histórica

\begin{tabular}{|c|c|c|c|c|}
\hline \multirow[b]{2}{*}{ Ciudad } & \multirow[b]{2}{*}{ Ciudad } & \multicolumn{3}{|c|}{ Relación con la memoria histórica } \\
\hline & & Fosas (cadáveres) & Fecha & Reconocimiento (año) \\
\hline Algeciras & Cementerio Viejo & $1(14)$ & 1936 & $\begin{array}{l}\text { Municipal (desconocido) } \\
\text { Asociativo (2015) }\end{array}$ \\
\hline Almería & San José & $7(358)$ & $1939-1945$ & - \\
\hline Cádiz & San José & 1 (desconocido) & 1936 & - \\
\hline \multirow[t]{2}{*}{ Córdoba } & Nuestra Señora de la Salud & $1(811)$ & 1936 & LMHAуFC (2012) \\
\hline & San Rafael & $1(1.473)$ & 1936 & LMHAуFC (2012) \\
\hline Dos Hermanas & San Pedro & 2 (más de 2.000) & 1937 & Familiar (1937) y municipal (1990) \\
\hline Granada & San José & $1(2.992)$ & 1936 & $\begin{array}{l}\text { Familiar-asociativo (2010) } \\
\text { Lмнауғс (2012) }\end{array}$ \\
\hline Huelva & Nuestra Señora de la Soledad & 1 (aprox. 5.000) & Desconocida & Municipal \\
\hline Jaén & San Eufrasio & $3(1.234)$ & 1939 & Munic., provin., autonómico, estatal y familiar (2007) \\
\hline Málaga & San Rafael & $1(4.571)$ & $1937-1957$ & $\begin{array}{c}\text { LMHAуFC (2012) } \\
\text { Municipal, autonómico y estatal (2007 y 2014) }\end{array}$ \\
\hline Marbella & San Bernabé & $1(72)$ & Desconocida & Municipal (1983) \\
\hline Sevilla & San Fernando & 6 (más de 3.600) & 1936-1955 & Municipal (2002) \\
\hline
\end{tabular}

Fuente: Dirección General de la Memoria Histórica (en línea). Elaboración propia.

Si dentro de medio milenio los jerezanos del futuro se topasen con los restos de una necrópolis árabe en las inmediaciones del actual cementerio municipal de Jerez, se encontrarían con una llamativa peculiaridad: la gran mayoría de restos pertenecerían a niños. [...]. Será por cuestiones de apego, o bien por proximidad para las visitas de los familiares a sus seres queridos, pero la cuestión es que de la treintena de tumbas [...] una amplia mayoría la suponen las de niños, bebes y fetos. «Como no les ha dado tiempo a conocer su tierra ni a su familia, duele menos dejarles aquí», explica el guía espiritual musulmán [Mustafá Boukhari]. (Juan Blanco, 2010)

El jardín del parque cementerio [de Málaga] en el que se instaló la muestra de esculturas se transforma en un espacio dedicado al arte contemporáneo. [...] La exposición, cuyo libro se presentó ayer, se instaló [...] en el Jardín del Recuerdo, espacio habilitado a la entrada del parque cementerio para que los familiares puedan depositar las cenizas de los incinerados y dedicar un árbol a su memoria. En total se presentaron 22 esculturas e instalaciones [...]. Ana Navarro, en su intervención, recordó que el arte ha estado relacionado con los lugares de enterramiento desde el principio de la especie humana. (Parque Cementerio de Málaga, en línea)

\section{b) Legendarias}

También es conocido el nicho de Antonio Mena Vicario [en el Cementerio Viejo de Algeciras], más conocido como el Santito o el Soldado; según cuentan, un joven se le apareció a una mujer que estaba limpiando una tumba y este le pidió a la joven que por favor limpiara una tumba que había cerca y que estaba muy abandonada. La joven se dirigió a la lápida y al acercarse vio una fotografía, se dio la vuelta asombrada al comprobar que el joven era el mismo que el de la foto. Desde entonces son muchos los algecireños que se acercan a su sepultura para pedirle favores, y su nicho siempre está lleno de flores, velas y de exvotos. (Grupo de Patrimonio Cementerio de Algeciras, 2012)

La vieja leyenda británica que lo envuelve [al Cementerio Inglés de Málaga] y que asegura que la última persona que es enterrada en un cementerio se convierte en su guardián. También existe la leyenda de que un personaje conocido, Antonio Alcaide, último guardián-jardinero del cementerio, ha sido observado vagando por el cementerio por los vecinos del mismo. ( «Málaga-Cementerio Inglés», Memorias de Andalucía, en línea, a)

En 1880, Antonio Susillo realizó su obra cumbre, El Cristo de las Mieles [en el cementerio de San Fernando de Sevilla], un Cristo crucificado esculpido según el canon de la escultura barroca sevillana. Se llama así porque poco después de colocado en su lugar, y tras la inhumación de Susillo a sus pies, los visitantes observaron que manaba miel de la garganta y del pecho de la imagen: las abejas habían hecho un panal en la boca de la imagen. («Sevilla-Cementerio de San Fernando», Memorias de Andalucía, en línea, $b$ ) 


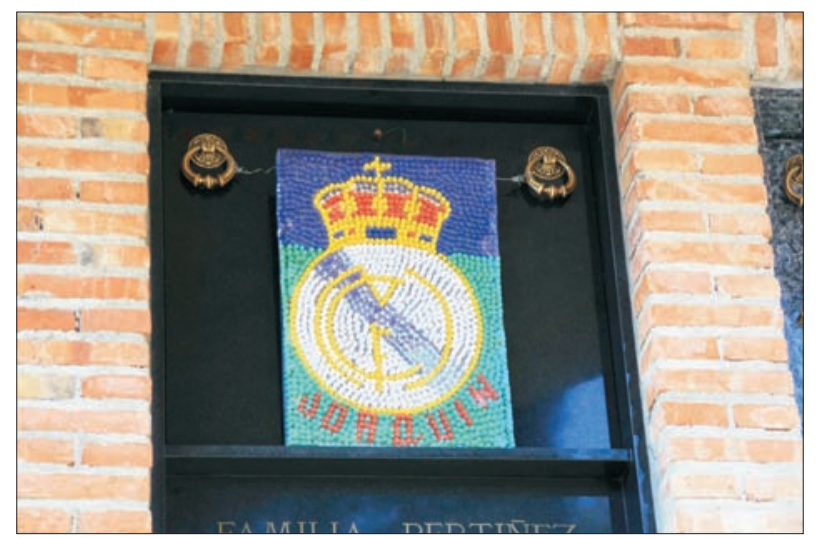

Fig. 13. Afición más allá de la muerte. Cementerio de San José de Granada. Fotografía del autor.

\section{CONSIDERACIONES FINALES}

\section{RESPECTO A LA COMPLEJIDAD PATRIMONIAL DE LOS CEMENTERIOS}

Probablemente no hay ningún bien patrimonial de la complejidad de los cementerios. Pese a su escaso y parcial reconocimiento, son, al mismo tiempo, realidad y símbolo; nostalgia presente y deseo de futuro; anonimato y proyección social de todo cuanto acontece en una ciudad. De una forma u otra, toda la riqueza cultural urbana, material e inmaterial, tiene correlato en su cementerio. Esto hace muy complejo el análisis de sus valores patrimoniales, asumidos mayoritariamente desde el punto de vista artístico, histórico o antropológico, pero de forma disociada. Este artículo, sin ánimo de exhaustividad, abre una perspectiva que unifica, tiempos, espacios y percepciones como argumento para crear visiones integradoras de todos los valores. En este sentido, concluye con la pregunta, más que con la certeza, de si no sería conveniente una figura específica de protección patrimonial para los cementerios, ya que con dificultad se pueden identificar y tutelar con las ya existentes.

\section{RESPECTO AL PROCESO DE PATRIMONIALIZACIÓN} DE LOS CEMENTERIOS DE LAS GRANDES CIUDADES ANDALUZAS

La consideración patrimonial de estas necrópolis es un proceso complejo en el que interfieren valoraciones y percepciones de muy distinto signo y en el que no siempre se han salvaguardado sus valores, en parte por su simple desconocimiento. En razón de la asignación de estos valores se pueden diferenciar distintos estadios de patrimonialización de las necrópolis analizadas:

\section{A) Cementerios en proceso de patrimonialización incipiente}

El reconocimiento básico más frecuente es el que procede de la valoración histórico-artística de la estructura, construcciones, esculturas y jardines de los cementerios analizados. Ésta viene recogida en la Base de Datos de Patrimonio Inmueble de la Junta de Andalucía a través de su Consejería de Cultura. Éste sería el caso de los cementerios de San José de Almería, de San Fernando en Jaén o de Nuestra Señora de la Merced en Jerez de la Frontera, y también el de Algeciras, donde, además de figurar en esta base de datos, la inhumación del guitarrista Paco de Lucía está convirtiendo el camposanto en un lugar de atracción de visitantes desde febrero de 2014.

Existe un no despreciable número de cementerios que, además de su inclusión en la base de datos citada, también se han constituido durante los últimos decenios en referentes regionales y nacionales para el movimiento de recuperación de la memoria histórica; aspecto este que refuerza su dimensión patrimonial. Es el caso de los cementerios de San Rafael en Córdoba, de Nuestra Señora de la Soledad de Huelva, de San Pedro de Dos Hermanas o de San Fernando de Sevilla. El cementerio de San Rafael de Málaga es un caso especial, pues, tras desmantelarse la práctica totalidad de sus estructuras, se construyó en él una pirámide con más de cinco mil nombres de personas condenadas a muerte durante la represión del «bando nacional», de las que más de cuatro mil fueron ejecutadas allí. Sin embargo, existe también una contestación a esta valoración patrimonial. Esto se traduce en debates ciudadanos y, en no pocas ocasiones, en la destrucción de los reconocimientos (placas, columnas y otros elementos evocadores) que, tanto institucional como familiarmente, se vienen incorporando a estos cementerios durante los últimos años. Esto prueba cómo la patrimonialización no es un proceso lineal y que, mucho menos, es compartido al mismo tiempo y con la misma intensidad por parte de todos los habitantes de un determinado lugar.

\section{B) Cementerios de condición patrimonial madura}

En esta circunstancia se encuentran aquellos camposantos que poseen un reconocimiento de rango internacional al haber sido admitidos en la Asociación Europea de Cementerios Singulares: Nuestra Señora de la Salud 
de Córdoba, San José de Granada o el Cementerio Inglés de Málaga, que es, además, bien de interés cultural; o sea, que alcanza la máxima protección patrimonial según la normativa legal española y andaluza. De hecho, este cementerio es a efectos de aprecio patrimonial el más conspicuo de los estudiados. También en Málaga ha alcanzado un alto nivel de reconocimiento una parte, la más burguesa, del antiguo cementerio de San Miguel, en buena medida desmantelado y convertido en un parque urbano tras su clausura en 1987. El cementerio de San Fernando de Sevilla posee un reconocimiento patrimonial que se traduce en la existencia de guías y, también, en el aprecio a su realidad formal y a la atribución de valores del imaginario popular respecto a personajes ilustres y conocidos allí enterrados (toreros, personajes del flamenco, etc.).

\section{C) Cementerios en despatrimonialización}

Aquí deben citarse los cementerios que han sido objeto del olvido. El de San José de Cádiz está condenado a la desaparición, en buena medida por su posición ya muy central en una ciudad sin capacidad de generar nuevas expansiones y cuyo desarrollo está vinculado siempre al recrecimiento. El otro es el de San Eufrasio en Jaén, que, cerrado en 2013 tras diez años sin enterramientos, se encuentra en ruinas a pesar de formar parte de la Base de Datos del Patrimonio Inmueble Andaluz, de haber sido incluido en la ampliación del conjunto histórico de la ciudad en 2011, de las propuestas de recuperación y musealización y de ser también un importante referente de la memoria histórica andaluza.

\section{RESPECTO A OTRAS DEBILIDADES IDENTIFICADAS EN LOS CEMENTERIOS ANALIZADOS}

Mientras que el proceso de patrimonialización institucional se asienta con bases más sistemáticas y conocimientos más precisos, la popular fluye con dificultad porque, a pesar de ser lugar de reposo de seres queridos o admirados, se encuentra al margen de la vida cotidiana salvo en fechas específicas; se relaciona con supersticiones ancestrales de negación de la muerte y no ha conseguido, por lo general, constituirse en un elemento identitario para la población local.

Además, hay que reseñar la escasez de fuentes sistematizadas para encontrar información de interés patrimonial sobre las necrópolis analizadas. A la carencia de obras de solvencia científica que se interesen en ellos de forma conjunta, hay que añadir la secular prevención, acrecentada en Andalucía, respecto a la muerte y sobre todo lo cercano a ella. Esto sería sólo anecdótico si no tuviese también repercusión en la necesaria implicación de las poblaciones para requerir una mejor protección y tutela de los cementerios. Información y reconocimiento de estos espacios a través de inventarios y catálogos adecuados son tareas pendientes y urgentes para fijar sus valores y establecer criterios que permitan preservarlos, sobre todo dando luz sobre qué debe ser conservado en ellos. Esto atañe tanto a la administración pública (especialmente a ayuntamientos y Junta de Andalucía) como al resto de la sociedad. Es urgente también un nuevo planteamiento urbanístico que evite que las migraciones futuras de estos equipamientos terminen relegando los cementerios a la «no ciudad», como sucede con el Parque Cementerio de Málaga, situado en un apartado lugar al occidente de la capital, o, peor aún, que como en el caso de Cádiz, una gran ciudad andaluza esté a punto de perder completamente la memoria solvente que siempre facilita un buen cementerio.

\section{BIBLIOGRAFÍA Y FUENTES DIGITALES}

Asociación PARA la ReCuPERACiÓn DE la Memoria HistóRICA (en línea): Asociación para la recuperación de la memoria histórica, <http://memoriahistorica.org.es>. [Consulta: 15-08-2015.]

Atienza, M. V. (1976): Marta \& María, Dardo, Málaga.

BÉCQuer, G. A. (1858-1864): Rimas y leyendas, [en línea] <www.ciudadseva.com/textos/cuentos/esp/becquer/rimyley/rimas_y_leyendas.htm $>$. [Consulta: 1108-2015.]

Blanco, J. (2010): «El cementerio musulmán de los niños». La Voz Digital. [en línea] <www.lavozdigital. es/cadiz/v/20100830/jerez/cementerio-musulmanninos-20100830.html> [Consulta: 30-08-2015.]

Calatrava, J. A. (1991): «El debate sobre la ubicación de los cementerios en la España de las Luces. La contribución de Benito Bails». Espacio, Tiempo y Forma, Serie VII, Historia del Arte, t. 4, pp. 349-366.

CAndéu, J. (2002): Antropología de la memoria. Nueva Visión, Buenos Aires.

CAno, J. A. (2013): «El Señor del cementerio de Granada». El Mundo. [en línea] <www.elmundo.es/anda lucia/2013/11/01/5272b78863fd3db30b8b4586.html. [Consulta: 20-09-2015.]

Coloma, L. (1873): Caín. Biblioteca de la Familia Cristiana, Madrid. 
Consejería de Cultura (en línea, $a$ ): Portal de Archivos de Andalucía. Consejería de Cultura de la Junta de Andalucía.

- (en línea, b) Portal de la Consejería de Cultura. Consejería de Cultura de la Junta de Andalucía, <www. juntadeandalucia.es/culturaydeporte/web>. [Consulta: mayo-septiembre de 2015.]

Consejería de Presidencia (1993): Actas del Primer Encuentro Internacional sobre los Cementerios Contemporáneos. Junta de Andalucía, Sevilla.

Cruz Morales, F.C. (1996): «Algunas expresiones de la muerte en la cultura popular tradicional andaluza», en V. Sánchez Ramos y J. Ruiz Fernández (eds.): Actas de las I Jornadas de Religiosidad Popular. Instituto de Estudios Almerienses, Almería, pp. 173-187.

Dirección General de Memoria Democrática: Mapa de fosas de las víctimas de la guerra civil y la posguerra en Andalucía. Junta de Andalucía, [en línea] <www. juntadeandalucia.es/administracionlocalyrelacionesinstitucionales/mapadefosas $>$. [Consulta: 06-07-2015.]

Gallego, I. (2015, en línea): «El Ayuntamiento inicia la rehabilitación del Cementerio Inglés para abrirlo al turismo». Huelva Información. [en línea] <www. huelvainformacion.es/article/huelva/2005483/ayuntamiento/inicia/la/rehabilitacion/cementerio/ingles/ para/abrirlo/turismo.html>. [Consulta: 14-09-2015.]

Girón Irueste, E., y A. Arenas Gómez (2003): «La imagen del Cementerio Inglés de Málaga en los viajeros extranjeros. La mirada del otro», en M. B. Villar García y P. Pezzi Cristóbal (eds.): Actas del I Coloquio Internacional sobre los Extranjeros en la España Moderna. Digarza, Málaga, pp. 359-368.

GonzÁlez DíAz, A. (1970): «El cementerio español en los siglos XVIII у XIX». Archivo Español de Arte, t. 43, núm. 171, pp. 289-320.

Grupo de Patrimonio Cementerio de Algeciras (2012): Plan Educativo del C. E. Per. Juan Ramón Jiménez. sobre el conocimiento del patrimonio andaluz de Algeciras. [en línea] <http://patrijrjimenez.blogspot.com.es/2012/12/cementerio-viejo-de-algeciras. html>. [Consulta: 22-09-2015.]

Instituto Andaluz del Patrimonio Histórico: Atlas de patrimonio inmaterial de Andalucía. IAPH/Consejería de Cultura, [en línea] <www.iaph.es/patrimonio-inmaterial-andalucia/frmSimple.do $>$. [Consulta: 04/0709-2015.]

Jiménez, J. R. (1978): Platero y yo. Círculo de Lectores, Barcelona.

JIMÉNEZ LOZANO, J. (2008): Los cementerios civiles y la heterodoxia española. Seix Barral, Barcelona, 1. 'ed. 1978.
LACARRIEU, M. (2011): «Procesos de patrimonialización material-inmaterial de los cementerios: valoración, transmisión y gestión». Portal de Unesco-Uruguay, [en línea] $<$ www.unesco.org.uy/ci/fileadmin/cultura/2011/procesos_de_patrimonializacion_de_los_cementerios_-_Monica_Lacarrieu.pdf>. [Consulta: 22-09-2015.]

Matero, F. G., y J. Peters (2003): «Survey Methodology for the Preservation of Historic Burial Grounds and Cemeteries». APT Bulletin, núm. 34, pp. 37-45.

Memorias de Andalucía (en línea, $a$ ): «MálagaCementerio Inglés», [en línea] <http://rotacode. com/!memoryinqr/Malaga---Cementerio-ingles-deSaint-George $>$. [Consulta: 11-09--2015.]

- (en línea, $b$ ): «Sevilla-Cementerio de San Fernando». [en línea] <http://rotacode.com/!memoryinqr/Sevilla---Elcementerio-San-Fernando $>$. [Consulta: 11-09-2015.]

MuÑoz GIL, J. (1990): «Los andaluces ante la muerte. Una aproximación desde la antropología cultural». El Folk-Lore Andaluz, núm. 7, pp. 21-31.

Nistal, M. (1996): «Legislación funeraria y cementarial española. Una visión espacial». Lurralde, núm. 19, pp. 29-53, [en línea] <www.ingeba.org/lurralde/ lurranet/lur19/19nistal/19nistal.htm>. [Consulta: 2108-2015.].

OcAÑA, J. M. (2006): «Tiempo pasado: cementerios malagueños». Diario Sur, [en línea] <www.diariosur.es/ prensa/20061115/malaga/tiempo-pasado-cementeriosmalaguenos_20061115.html>. [Consulta: 03-09-2015.]

PÁEz, J. (2012): «La tapia del cementerio de Granada». La Lamentable, [en línea] <http://lamentable.org/latapia-del-cementerio-de-granada-2>. [Consulta: 2308-2015.]

Parque Cementerio de Málaga (en línea): <www.parcema.com>. [Consulta: 22-09-2015.]

Prats, L1. (2005): «Concepto y gestión del patrimonio local». Cuadernos de Antropología Social, núm. 21, pp. 17-35.

Quirós LinAREs, F. (1991): Las ciudades españolas a mediados del siglo XIX. Ámbito, Valladolid, pp. 132-143.

Ragon, M. (1983): The Space of Death. A Study of Funerary Architecture, Decoration and Urbanism, University Press of Virginia, Charlottesville (Estados Unidos).

Rodríguez Barberán, F. J., y M. Ramos Guerra(1993): Cementerios de Andalucía. Arquitectura y urbanismo. Consejería de Obras Públicas y Transportes de la Junta de Andalucía, Sevilla.

Rodríguez BECERRA, S. (1997): «Rituales de muerte en Andalucía. Significados y funciones», en F. Checa y Olmos y P. Molina (eds.): La función simbólica de 
los ritos. Rituales y simbolismo en el Mediterráneo. Icaria, Barcelona, pp. 129-158.

SAAVEDRA, A. (Duque de Rivas): «Una antigualla de Sevi1la. Romance I», en Romances históricos. [en línea] Biblioteca Virtual Miguel de Cervantes, <www.cervantesvirtual.com/obra-visor/romances-historicos--0/ html/fedd0eaa-82b1-11df-acc7-002185ce6064_4. html>. [Consulta: 20-09-2015.]

SAnTONJA, J. L. (1998-1999): «La construcción de cementerios extramuros. Un aspecto de la lucha contra la mortalidad en el antiguo régimen». Revista de Historia Moderna. Anales de la Universidad de Alicante, núm. 17, pp. 34-44.

TARrés, S., y J. Moreras (2012): «Patrimonio cultural funerario. Los cementerios de las minorías religiosas en España», en B. Santamaría (ed.): Geopolíticas pa- trimoniales. De culturas, naturalezas e inmaterialidades. Una mirada etnográfica. Germanía, Valencia, pp. 267-283.

Tunbridge, J. E., y G. J. Ashworth (1996): Dissonant Heritage: the management of the past as a resource in conflicto. J. Wiley, Chichester.

Uzzell, D., y R. Ballantyne(1998): «Heritage thats hurts. Interpretation in a postmodern world», en D. Uzzell y R. Ballantyne (eds.): Contemporary Issues in Heritage and Environment Interpretation. The Stationery Office, Londres, pp. 152-171.

VÁzquez, A. (2015): «El retorno al campo del cementerio de San Rafael». La Opinión de Málaga, [en línea] <www.laopiniondemalaga.es/malaga/2015/01/17/ retorno-campo-cementerio-san-rafael/736625.html>. [Consulta: 15-09-2015.] 